\title{
IL-17A levels increase in the infarcted region of the left ventricle in a rat model of myocardial infarction
}

\author{
Ana María Ávalos' ${ }^{1}$ Felipe A. Apablaza ${ }^{1}$, Mariana Quiroz², Viviana Toledoํ, Juan Pedro Peña ${ }^{3}$, Luis Michea ${ }^{3}$, \\ Carlos E. Irarrázabal' ${ }^{2}$, Flavio A. Carrión ${ }^{1}$, Fernando E. Figueroa ${ }^{1}$ \\ ${ }^{1}$ Laboratorio de Inmunología Celular y Molecular, Facultad de Medicina, Universidad de los Andes. Santiago, Chile. \\ ${ }^{2}$ Laboratorio de Fisiología Molecular, Facultad de Medicina, Universidad de los Andes. Santiago, Chile. \\ ${ }^{3}$ Laboratorio de Fisiología Integrativa. Instituto de Ciencias Biomédicas (ICBM), Facultad de Medicina, Universidad de Chile. Santiago, Chile.
}

\begin{abstract}
Th17 cells, a recently described subtype of CD4+ effector lymphocytes, have been linked to cell-mediated autoimmune and inflammatory diseases as well as to cardiovascular diseases. However, the participation of IL-17A in myocardial ischemic injury has not been clearly defined. We therefore conducted the present study to evaluate IL-17A and Th17-related cytokine levels in a rat model of myocardial infarction (MI).

MI was induced in male Sprague Dawley rats by coronary artery ligation. Controls were sham-operated (Sh) or non-operated (C). Blood and samples from the left ventricle (LV) were collected at weeks 1 and 4 post-MI. At week 1, MI animals exhibited increased IL-6, IL-23 and TGF- $\beta$ mRNA levels with no apparent change in IL-17 mRNA or protein levels in whole LV. Only TGF- $\beta$ mRNA remained elevated at week 4 post-MI. However, further analysis revealed that IL-17A mRNA and protein levels as well as IL- 6 and IL-23 mRNA were indeed increased in the infarcted region, though not in the remote non infarcted region of the LV, except for IL-23 mRNA.

The increased expression of IL-17A and Th17-related cytokines in the infarcted region of LV, suggests that this proinflammatory pathway might play a role in early stages of post MI cardiac remodelling.
\end{abstract}

Key terms: Interleukin-17, Th17, myocardial infarction, cardiovascular disease.

\section{INTRODUCTION}

Myocardial infarction (MI) is the major cause of death and disability worldwide, and despite considerable advances in diagnosis and treatment, continues to be a major public health problem. Its main sequelae of myocardial remodelling and eventual progression to ventricular dysfunction and heart failure remain as problems not fully understood and also difficult to treat (Thygesen and Alpert, 2007)

Since the sentinel description of inflammatory cytokines in patients with heart failure in the 90's by Levine (Levine et al.,1990), there has been growing interest in the role that these molecules play in regulating cardiac structure and function, particularly regarding their role in disease progression (Nian et al., 2004; Mann 2009). Animal models of MI have shown that pro-inflammatory cytokines are involved in cardiac remodelling: in rats, for example, TNF- $\alpha$, interleukin (IL)$1 \beta$ and IL-6 levels increase significantly in the left ventricle (LV) after MI ( Li et al., 2006; Deten et al., 2002; Ono et al., 1998). Also CD4+ T helper (Th) dependent responses have been shown to play a role in the pathogenesis of several cardiovascular diseases (Baidya and Zeng, 2005). Clinical and experimental studies have shown that increased Th1-associated inflammatory responses and decreased Th2-type antiinflammatory responses are associated with the pathogenesis of atherosclerosis (Baidya and Zeng, 2005), and acute coronary syndromes (ACS) including acute MI and unstable angina pectoris (Cheng et al., 2005; Pasqui et al., 2005; Methe et al., 2005; Steppich et al., 2007).
Th17 cells are a recently described effector T-cell subset that secretes mainly pro-inflammatory cytokines including IL-17, IL-6 and tumor necrosis factor alpha (TNF- $\alpha$ ) (Harrington et al., 2005; Langrish et al., 2005; Park et al., 2005). Transforming growth factor-beta (TGF- $\beta$ ), IL-21 and IL-6 are required for induction of Th17 differentiation whereas IL-23 plays an important role in expanding and stabilizing the Th17 phenotype (Awasthi and Kuchroo, 2009, Mangan et al., 2006). IL-23 also induces proinflammatory effector cytokines in Th17 cells. Therefore, similar to the effect of IL-12 for Th1 development, IL-23 plays a fundamental role in stabilizing the Th17 lineage and promoting Th17 responses, even if the initial steps of Th17 differentiation might be independent of IL-23 (Aggarwal et al., 2003). Thus, IL-23 has been considered essential for full differentiation and effector function of Th17 cells (Chen et al., 2011). Th17 cells have not only been shown to exert a pathogenic role in autoimmune and inflammatory conditions (Langrish et al., 2005; Awasthi and Kuchroo, 2009; Chen et al., 2006) but more recently have also been associated with cardiovascular diseases (Cheng et al., 2008). Indeed, several studies now indicate that inflammation is a major factor contributing to the pathophysiology of cardiovascular diseases and that Th17 cells are involved in myocardial injury, hypertrophy, and remodelling. Patients with dilated cardiomyopathy reveal increased peripheral Th17 numbers, Th17 related cytokines (IL-17, IL-6 and IL-23) and transcription factors. (Yi et al., 2009). Importantly, a role for Th17 cells has also been suggested in ischemic heart disease. Observations in patients with ACS revealed a significant increase in peripheral 
Th17 cell numbers and Th17-related cytokines (IL-17, IL-6, and IL-23) (Jafarzadeh et al., 2009; Liang et al., 2009; Hashmi and Zeng, 2006). In fact, a concurrent decrease in the number of anti-inflammatory $\mathrm{T}$ regulatory (Treg) cells and Treg-related cytokines - (IL-10 and transforming growth factor (TGF- $\beta 1$ ) in these patients indicates that a proinflammatory Th17/Treg imbalance could be a feature also of the ACS (Cheng et al., 2008). More recently, the finding that the expression of IL-17 cytokines and their receptors are elevated during myocardial ischaemia/reperfusion injury also suggest that IL-17 may play a role in post-infarct inflammatory and apoptotic responses (Barry et al., 2011; Liao et al., 2012). Altogether, these results suggest that IL-17 might play a role in the onset of MI but further studies are needed to clarify whether the IL-23/IL-17 axis, along with other cytokines or independently, regulates the progression of MI and ventricular remodelling. Therefore, the aim of this study was to evaluate the activation of the IL-23/IL17 axis in a rat model of acute MI.

\section{MATERIALS AND METHODS}

\section{Experimental myocardial infarction}

Male Sprague Dawley rats, (200 g) were maintained under standard environmental conditions, with food and water ad libitum. Myocardial infarction was induced (MI group), as described previously ( Bhindi $\mathrm{R}$ et al., 2006). Rats were anesthetized with i.p. ketamine $(50 \mathrm{mg} / \mathrm{kg})$ and xylazine $(10$ $\mathrm{mg} / \mathrm{kg}$ ), intubated and ventilated mechanically (Columbus Instruments Model 121). After thoracotomy the left anterior descending coronary artery was ligated with silk suture (Hospital \& Diagnostics Supplies Ltda). Following coronary occlusion, the chest was closed and after extubation, animals received oral analgesia with tramadol $(5 \mathrm{mg} / \mathrm{kg}$ weight). Serum and LV samples were collected at week 1 (MI-1 week) and week 4 (MI-4 weeks) post procedure. Sham (Sh) operated rats (Sh-1 week and Sh-4 weeks) underwent the same procedure, but with no coronary ligation. Non-operated rats also served as controls (C).

Experimental procedures and protocols were performed according to the US National Institutes of Health Guide for the Care and Use of Laboratory Animals (NIH Publication No. 85-23, revised 1996) and were approved by the Institutional Animal Care and Use Committee of the Universidad de los Andes School of Medicine and the Fondecyt Bioethics Advisory Committee in Chile.

\section{Animal euthanasia and samples collection}

For euthanasia, animals were anesthetized with ketamine (50 $\mathrm{mg} / \mathrm{kg})$ and xylazine $(10 \mathrm{mg} / \mathrm{kg})$ i.p. and hearts were injected with intraventricular $10 \%$ potassium chloride, according to the American Veterinary Medical Association (AVMA) Guidelines on Euthanasia. Hearts without a transmural infarction or an infarct scar size $<20 \%$ of LV perimeter upon visual examination were excluded from the study in order to evaluate only infarctions of at least moderate size (Schoemaker et al., 1990). The LV was then dissected, weighted and a transversal section including the infarcted zone was extracted and fixed with $10 \%$ formaldehyde for histological analysis, while a contiguous section of the LV was reserved for RNA and protein extraction. $20 \mathrm{mg}$ samples were taken from the non- infarcted zone (or analogous region from Sh group samples) and kept in RNAlater ${ }^{\circledR}$ solution (Ambion) until RNA extraction. The remaining LV was homogenized with Complete Lysis-M reagent and protease inhibitor cocktail (Roche). To assess cytokine expression in the infarcted zone of LV, we employed a second group of MI-1 week animals to extract RNA and protein samples exclusively from the infarcted region (MI-IR) and from the remote non-infarcted region of the LV (MI-RR), contralateral to the infarcted one (Figure 1). A Sh group was also used for these experiments.

\section{Assessment of cardiomyocyte hypertrophy and infarct size}

Hypertrophy was quantified as the average cardiomyocyte cross sectional area in paraffin embedded sections of $6 \mathrm{~mm}$ of thickness of the LV, stained with haematoxylin and eosin. Microphotographs were obtained at high magnification for each section and the cross sectional area and perimeter of at least 15 cells from 5 different fields was quantitated by a blind observer using ImageJ software (NIH). To assess the infarct scar size, paraffin sections were stained for 90 minutes with Sirius red. In each section the collagen-positive area was calculated as the area occupied by red-stained collagen divided by the total tissue area. The same pictures used for fibrotic area determination were also used for infarct size estimation by measuring the perimeter of infarcted tissue and dividing it by the perimeter of the complete left ventricle ( Fishbein et al., 1978; Pfeffer et al., 1979)

Quantitation of IL-17A and IL-6 expression in cardiac tissue and plasma by ELISA

Protein content in extracts was measured using a BCA protein assay kit (Pierce). ELISA kits were used to quantitate left ventricle levels of IL-17A (eBioscience) and IL-6 (Thermo Scientific) in LV homogenates and plasma. Absorbance was measured by ELISA reader (Bio-Tec) at $450 \mathrm{~nm}$ and results were expressed as $\mathrm{pg} / \mathrm{ml}$ for plasma or $\mathrm{pg} / \mathrm{mg}$ of protein for the LV homogenates.

RNA isolation and semi-quantitative reverse transcriptase chain reaction (RT-PCR) analysis of cytokines

Total cellular RNA was extracted from tissue samples with Trizol (Invitrogen), according to the manufacturer's instructions. Reverse transcription reaction was performed with ImProm-IITM Reverse Transcriptase in a thermocycler (Maxygene Thermal Cycler, Axygen). For PCR reaction, the following oligonucleotides were used as rat sense and antisense primers, respectively. IL-17A (247 bp): 5'-CTTCACCCTGGACTCTGAGC-3', 5'-TGGCGGACAATAGAGGAAAC-3'; IL-6 (218 bp): 5'-AGTTGCCTTCTTGGGACTGA-3', 5'- ACAGTGCATCATCGCTGTTC-3'; TGF-b1 (187 bp): 5'-GACCTGCTGGCAATAGCTTC-3', 5'-GGGTCTCCCAAGGAAAGGTA-3'; IL-23, $\alpha$ subunit p19 (152 bp): 5'- CAGGTTCCCATGGCTACAGT-3', 5'-TCTGGGGTTTGTTGCTTTTC-3'; IL-1 $\beta$ (248 bp): 5'-CAGCAATGGTCGGGAC-3', 5'-ATAGGTAAGTGGTTGCCT-3'; TNF- $\alpha$ (209 bp): 5'-TGATCCGAGATGTGGAACTG-3'; 5'-GGCCATGGAACTGATGAGAG-3' and glyceraldehyde 3-phosphate dehydrogenase (GAPDH, $156 \mathrm{bp}$ ): 5'-CACGGCAAGTTCAACGGC-3'， 5'-GGTGGTGAAGACGCCAGTA-3'. 
Conventional PCR reactions were performed in a thermocycler (Maxygene Thermal Cycler, Axygen) and the PCR products were visualized on $2 \%$ agarose gels, photographed and analyzed with ImageJ software for semi-quantitative assessment. Real time PCR reactions were performed in a Chromo 4 (Bio Rad) thermocycler/detector. The mRNA levels were expressed relative to the amount of GAPDH mRNA present in each sample.
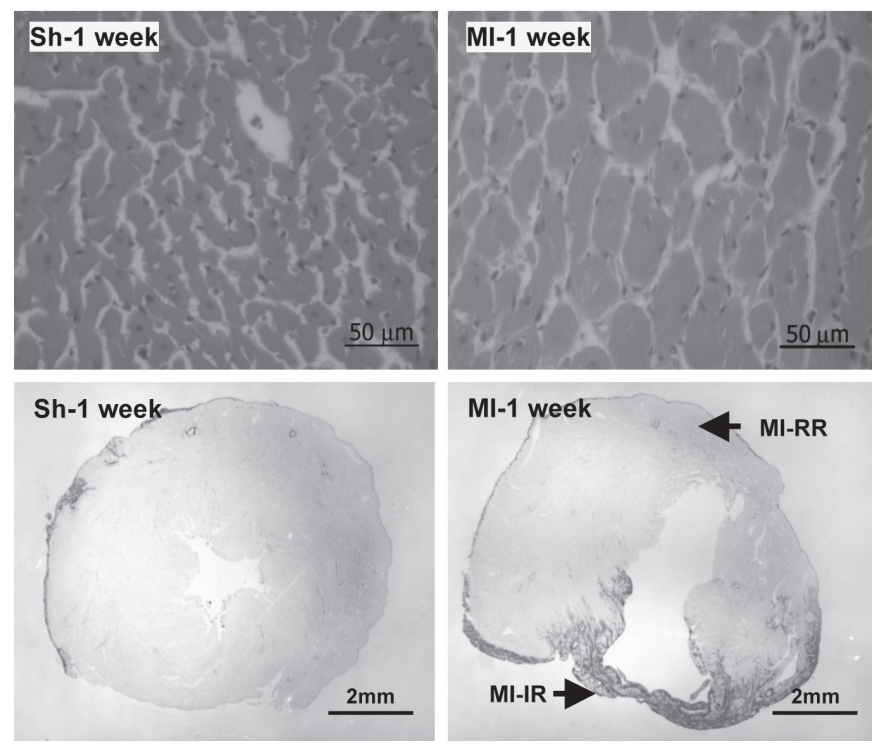

Figure 1: Cardiomyocyte hypertrophy and left ventricle (LV) scar formation after MI. Top left and middle: Representative microphotographs of LV myocardium stained with H\&E in Shamoperated (Sh-1 week) and infarcted rats (MI-1 week). Bottom left and middle: Representative photographs of hearts from Shamoperated (Sh-1 week) and infarcted rats (MI-1 week) at week 1 post MI stained with sirius red. MI-RR: Myocardial infarctionremote region, MI-IR: Myocardial infarction-infarcted region.
Localization of IL-17A by immunohistochemistry

Immunohistochemistry was used to confirm IL-17A expression in the MI-IR and MI-RR of the LV. Paraffin embedded sections (5 mm thickness) underwent microwave heating in citrate buffer as antigen recovery method. Sections were blocked with casein and as primary antibody a polyclonal rabbit AntiIL17A human IgG (Santa Cruz Biotechnology, Sta. Cruz, CA, SC-7927) was used in 1:300 dilution. As secondary antibody a polyclonal goat anti-rabbit IgG biotinylated (Vector Lab. UK, BA-1000) was used in 1:3000 dilution and incubated with peroxidase conjugated streptavidin. Control experiments without the primary antibody were performed to rule out the possibility of secondary antibody artifacts. Sections were stained with diaminobenizidine (Vector Lab. UK, ImmPACT ${ }^{\mathrm{TM}}$ DAB substrate, SK-4105) and lightly counterstained with hematoxylin (Vector Lab. UK, VECTOR Hematoxylin, H-3401) before dehydration. Histological sections were observed under light microscope to identify positive staining in the infarcted and non-infarcted regions of LV.

\section{Statistical analysis}

Comparisons of means between groups were performed by Kruskar-Wallis test and post hoc analyses were performed with Mann-Whitney test. For all analyses we used the statistical software SigmaStat (SigmaStat3, San Diego, CA, USA).

\section{RESULTS}

\section{Mortality, Infarct Size and Chamber Dimensions}

Mortality after the surgical procedure was similar among experimental groups (Table 1). After excluding rats with MI sized under $20 \%$, data was obtained for 45 animals, according to the following groups: Sham group at week 1 (Sh-1 week; $\mathrm{n}=11$ ), MI group at week 1 (MI-1 week, $\mathrm{n}=15)$, Sham group at week 4 (Sh-4 weeks, $\mathrm{n}=7$ ), MI group at week 4 (MI-4 weeks, $\mathrm{n}=7$ ). No significant differences in MI size were found between

\section{TABLE 1}

Hemodynamic data, cardiomyocyte hypertophy and scar formation in the LV after sham operation or myocardial infarction (MI) at 1 and 4 weeks

\begin{tabular}{|c|c|c|c|c|}
\hline Experimental Group & Sh-1 week & MI-1 week & Sh-4 weeks & MI-4 weeks \\
\hline Mortality $(\%)$ & 33 & 29 & 36 & 36 \\
\hline $\mathrm{n}$ & 11 & 15 & 7 & 7 \\
\hline MI size $(\%)$ & 0 & $35.1 \pm 2.9$ & 0 & $31.7 \pm 3.1$ \\
\hline $\mathrm{BM}(\mathrm{g})$ & $230 \pm 7$ & $205 \pm 10$ * & $335 \pm 16$ & $335 \pm 25$ \\
\hline $\mathrm{VM}(\mathrm{mg})$ & $590 \pm 21$ & $571 \pm 25$ & $887 \pm 48$ & $1032 \pm 69$ * \\
\hline RVM (mg/g) & $2.56 \pm 0.04$ & $2.78 \pm 0.05$ * & $2.74 \pm 0.10$ & $3.12 \pm 0.15$ * \\
\hline Cardiomyocyte cross-sectional area $\left(\mathrm{mm}^{2}\right)$ & $288 \pm 6$ & $423 \pm 41$ * & $308 \pm 31$ & $419 \pm 57$ \\
\hline Cardiomyocyte perimeter $(\mu \mathrm{m})$ & $69 \pm 1$ & $82 \pm 4^{*}$ & $71 \pm 3$ & $84 \pm 8$ \\
\hline Scar area in the LV $(\%)$ & $0 \pm 0$ & $13.8 \pm 1.5^{*}$ & $0 \pm 0$ & $16.1 \pm 3.1$ * \\
\hline
\end{tabular}

Sh-1 week: Sham operated rats at week 1, MI-1 week: myocardial infarction at week 1, Sh-4 weeks: Sham operated rats at week 4, MI-4 weeks: myocardial infarction at week 4, n: number of rats in each group after mortality, MI size: myocardial infarction size, BM: body mass, VM: ventricular mass, RVM: relative ventricular mass (VM/BM), LV: left ventricle. Data are presented as mean \pm SEM. $\left(^{*}\right) \mathrm{p}<0.05$, Sh group vs MI group at each time after surgery. 
the MI-1 week and MI-4 weeks groups (Table 1). Body mass (BM) was reduced in the MI group only at week 1 (MI-1 week: $205 \pm 10 \mathrm{~g}$ vs Sh-1 week: $230 \pm 7 \mathrm{~g}, \mathrm{p}<0.05$ ) (Table 1). Total ventricular mass $(\mathrm{VM})$ increased significantly at week 4 (MI4 weeks: $1032 \pm 69 \mathrm{mg}$ vs Sh-4 weeks: $887 \pm 48 \mathrm{mg}, \mathrm{p}<0.05)$ and relative ventricular mass (RVM, calculated as VM (mg)/ BM (g)) increased in MI groups at week 1 (MI-1 week: 2.78 \pm 0.05 vs Sh-1 week: $2.56 \pm 0.04, \mathrm{p}<0.05)$ and week 4 (MI-4 weeks: $3.12 \pm 0.15$ vs Sh-4 weeks: $2.74 \pm 0.10, \mathrm{p}<0.05$ ). (Table 1). No differences were observed between control group (nonoperated rats) and Sham group at week 1 in all parameters studied (data not shown). According to Yin et al (1982), the use of body mass instead of tibia length permits a more accurate quantification of cardiac hypertrophy. However, we observed a close correlation between RVM calculated by body mass and the histological measurements corresponding to myocyte diameter and cellular cross-sectional areas in the infarcted rats.

Cardiomyocyte hypertrophy, cardiomyocyte perimeter and scar formation in the LV.

Compared with Sh groups, average LV cardiomyocyte crosssectional area was higher in MI group than in Sh group at week $1\left(423 \pm 41 \mu \mathrm{m}^{2}\right.$ vs $\left.288 \pm 6 \mu \mathrm{m}^{2}, \mathrm{p}<0,05\right)$ (Table 1, Figure 1). Similarly, the cardiomyocyte perimeter was significantly higher in the MI group compared with Sh group at week 1 after MI (82 $\pm 4 \mu \mathrm{m}$ vs $69 \pm 1 \mu \mathrm{m}, \mathrm{p}<0.05)$. As expected, we confirmed scar formation only in the MI group and not in control or Sh animals (Table 1, Figure 1). We found no differences in LV MI scar area among MI-1 week and MI-4 weeks groups (13.8 \pm $1.5 \%$ vs $16.1 \pm 3.1 \%$ respectively). No significant changes were observed in these parameters studied between control group and sham group at week 1 (data not shown).

MI increased IL-6, IL-23 and TGF- $\beta$ expression in LV region at week 1 post MI

Relative mRNA levels of IL- 6 , IL-23, TGF- $\beta$, IL- $1 \beta$ and TNF- $\alpha$ were measured in the LV after MI by conventional PCR and expressed in relation to GAPDH (Figure. 2). MI group exhibited increased transcription of IL- 6 respect to the Sh group at week 1 post infarction $(0.63 \pm 0.19$ vs $0.0 \pm 0.0, \mathrm{p}<0.05)$ $(2, \mathrm{~A})$ and also of IL-23 (1.09 \pm 0.11 vs $0.36 \pm 0.06, \mathrm{p}<0.05)(2, \mathrm{~B})$ and TGF- $\beta(1.41 \pm 0.08$ vs $0.70 \pm 0.06, \mathrm{p}<0.05)(2, \mathrm{C})$. At week 4 , TGF- $\beta$ levels in the MI group remained higher than in the corresponding Sh group $(1.15 \pm 0.02$ vs $0.61 \pm 0.09, \mathrm{p}<0.05)$, while IL-23 levels in the MI group were indistinguishable from those in Sh animals $(0.91 \pm 0.10$ vs $0.77 \pm 0.08)$. IL-6 decreased to undetectable levels in both groups. No changes in the transcription of IL- $1 \beta(0.74 \pm 0.23$ vs $0.59 \pm 0.16)(2, \mathrm{D})$ nor TNF- $\alpha(0.86 \pm 0.17$ vs $0.63 \pm 0.21)(2, E)$ were detected. Even if the elevation of TGF- $\beta$, IL- 6 and IL- 23 suggested an activation of the Th17 pathway in response to MI, this was not associated with an increase of IL-17A expression in the whole LV nor in the mRNA levels of IL-17 at weeks 1 and 4 (data not shown). This unexpected finding led us to compare the expression of these cytokines more specifically in the infarcted region (MI-IR) and remote non-infarcted region (MI-RR) of the LV.
A

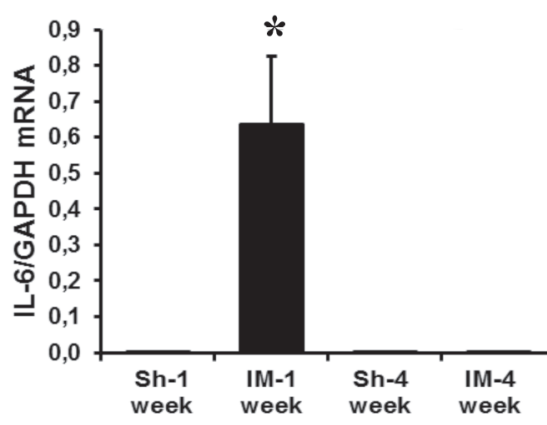

D

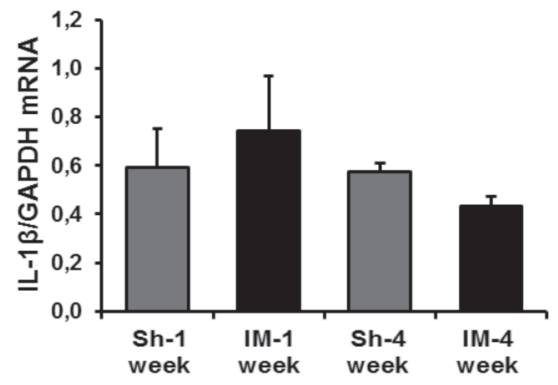

B

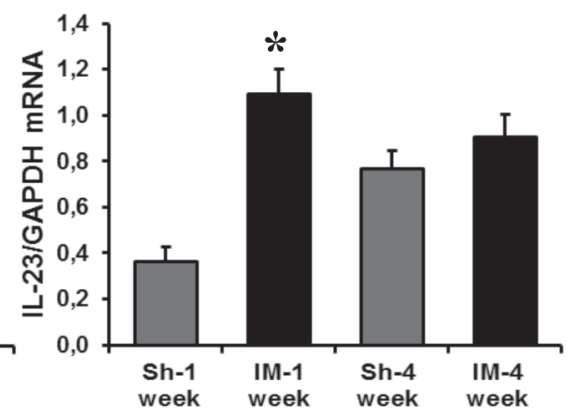

E

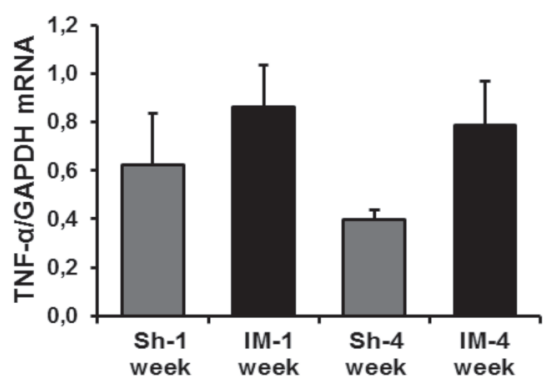

C

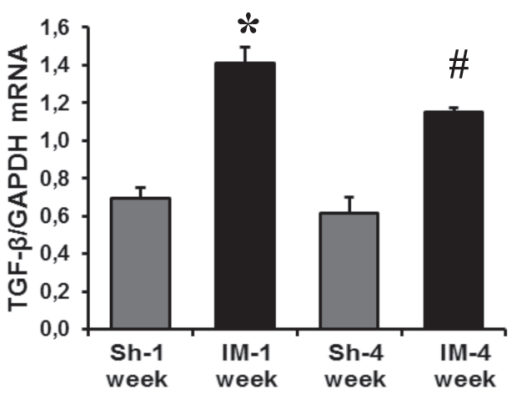

Figure 2: Relative expression of IL-6, IL-23, TGF- $\beta$, IL-1 $\beta$ and TNF- $\alpha$ mRNA after MI. (A to E): mRNA extracted from LV samples (A to E) from Sham (Sh) and infarcted rats (MI) was analyzed for the expression of cytokines by conventional PCR. Results are expressed as mean \pm SEM, $\mathrm{p}<0.05$. (*) $\mathrm{p}<0.05 \mathrm{Ml}-1$ week vs Sh-1 week, (\#) $\mathrm{p}<0.05 \mathrm{Ml}-4$ weeks vs Sh-4 weeks and vs Sh-1 week. $\mathrm{n}=4$ to 7 per group. 
$M I$ increased $I L-17$ A expression in the infarcted region of the $L V$

We therefore analyzed tissue samples of MI-IR and MI-RR of the LV of infarcted rats at week 1 post MI to measure IL-17A and IL-6 mRNA levels by real time PCR (Figure. 3). MI significantly increased IL-17A mRNA levels in the MI-IR respect to MI-RR of infarcted animals $(7.6 \pm 1.6$ vs $0.3 \pm 0.2, \mathrm{p}<0.05)$ or to Sh samples $(0.1 \pm 0.0, \mathrm{p}<0.05)$ (Figure. $3, \mathrm{~A})$. As expected, there was no difference in IL-17A mRNA levels between MI-RR and Sh samples. MI animals also exhibited increased IL-6 mRNA levels in the MI-IR versus MI-RR $(296.5 \pm 30.9$ vs $5.8 \pm 3.4, \mathrm{p}<0.05)$ and levels of this cytokine was higher in the MI-RR than in Sh heart samples (5.8 \pm 3.4 vs $1.6 \pm 1.6, \mathrm{p}<0.05)$ (Figure. 3, B).

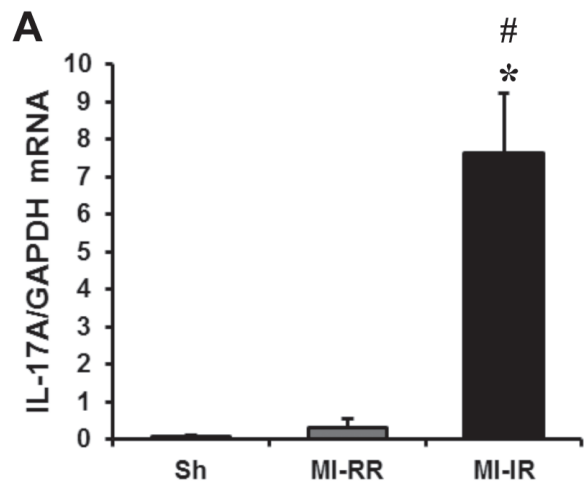

C

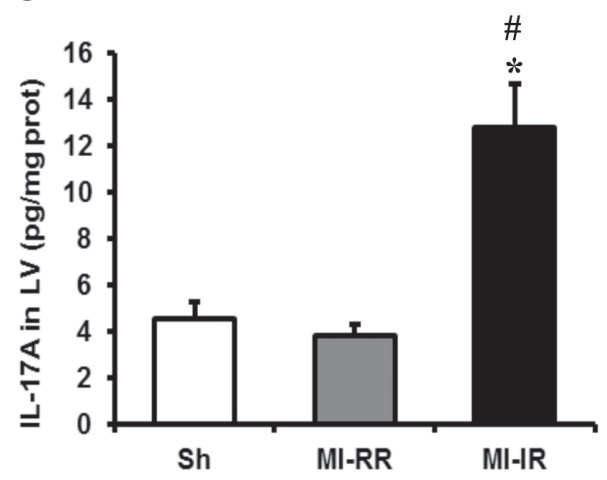

E

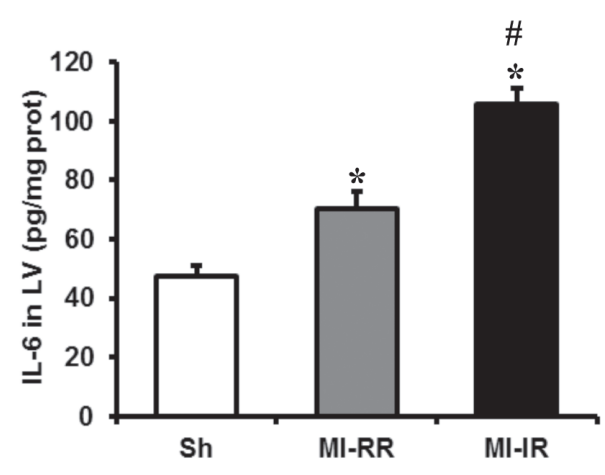

Expression of IL-17A and IL-6 were also quantitated in LV protein extracts from MI-IR, MI-RR and in plasma of MI and Sh rats by ELISA (Figure. 3). In accordance with mRNA expression, MI significantly increased IL-17A protein levels in the MI-IR respect to both MI-RR $(12.8 \pm 1.8 \mathrm{pg} / \mathrm{mg}$ vs $3.8 \pm$ $1.5 \mathrm{pg} / \mathrm{mg}, \mathrm{p}<0.05)$ and Sh samples $(4.5 \pm 0.7 \mathrm{pg} / \mathrm{mg}, \mathrm{p}<0.05)$ (Figure. 3, C). MI also increased IL-6 protein levels in the MI-IR respect to MI-RR $(105.7 \pm 5.3 \mathrm{pg} / \mathrm{mg}$ vs $70.4 \pm 6.0 \mathrm{pg} /$ $\mathrm{mg}, \mathrm{p}<0.05)$ and to Sh $(47.3 \pm 3.6 \mathrm{pg} / \mathrm{mg}, \mathrm{p}<0.05)$, with levels being higher also in MI-RR than Sh $(\mathrm{p}<0.05)$ (Figure. 3, E). We also found slightly increased levels of IL-17A and IL-6 in the plasma of infarcted rats but this tendency was not statistically significant (Figure. 3, D and F).

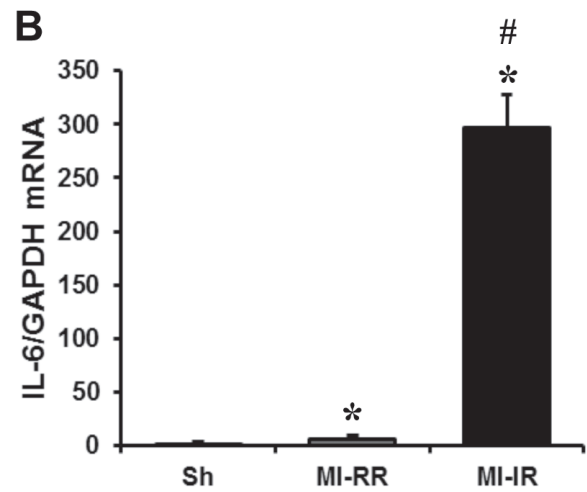

D

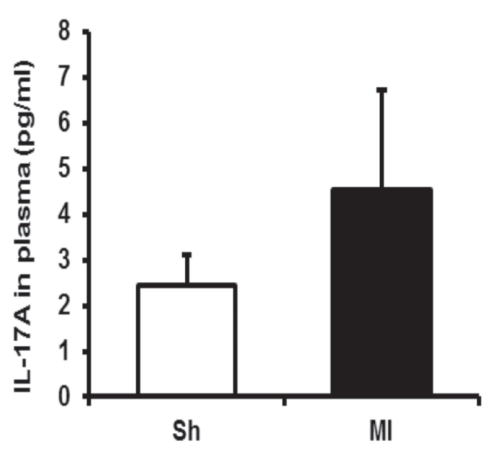

$\mathbf{F}$

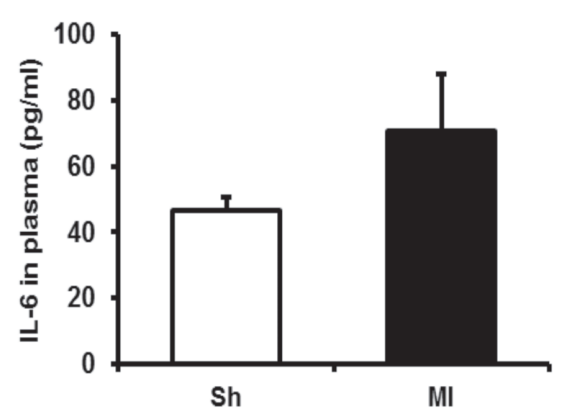

Figure 3: mRNA expression of Th17-related cytokines in left ventricle (LV) and protein levels of IL-17A and IL-6 in LV and plasma, 1 week after MI. (A and B): mRNA extracted from LV samples from Sham (Sh) and infarcted rats (MI) was analyzed for the expression of IL-17A, and IL-6 by real time PCR. (C to F): Total protein extracts (C and E) and plasma samples (D and F) from Sham-operated (Sh) and infarcted rats (MI) at week 1 post MI were analyzed by ELISA for IL-17A and IL-6 levels. MI-RR: samples from MI remote region, MI-IR: samples from MI infarcted region. Results are expressed as mean \pm SEM. $\left(^{*}\right) \mathrm{p}<0.05$ vs $\mathrm{Sh},(\#) \mathrm{p}<0.05$ vs MI-RR. n=6 per group. 
To look for in situ IL-17A in infarcted hearts we performed immunohistochemical staining of MI-IR sections from week 1 MI and sham animals (Figure. 4). Staining was positive for IL17A in MI animals but only in the MI-IR of the LV. In addition, we found positive staining suggestive of an endothelial pattern in most areas of the infarction scar (Figure. 4, left) and few small positive cells in the vicinity of blood vessels (Figure. 4, middle, arrows). As expected, no staining was found on the MI-RR of MI group (Figure. 4, right) nor in the Sh group samples (data not shown).

\section{DISCUSSION}

This is the first report of an increase in IL-17 and Th17-related cytokines in the LV after permanent coronary occlusion in a rat model of MI. We found increased IL-6, IL-23 and TGF- $\beta$ mRNA levels in the LV at one week post-MI, without significant changes in IL-17A, IL-1 $\beta$ or TNF- $\alpha$ expression. Only TGF- $\beta$ mRNA remained elevated at week 4 post-MI.

Even if the increases in IL-6, IL-23 and TGF- $\beta$ indeed suggested an activation of the IL-23/IL-17 axis, we could not detect a concomitant increase of IL-17A mRNA in the whole LV samples. We therefore looked for IL-17A expression specifically in the infarcted region of the LV (MI-IR) and compared IL17A and IL-17 related cytokines in the infarct and the remote non-infarcted LV region (MI-RR), at week1 post-MI. With this approach, we found increased IL-17A mRNA and protein levels in the infarcted region and also corroborated the increase of IL-6 which was present at higher levels in the MI-IR than in the MI-RR of the heart.

Th17 cells are a CD4+ $\mathrm{T}$ helper subset that plays crucial effector functions in inflammatory and autoimmune processes (Harrington et al., 2005; Park et al., 2005). IL-6, IL21 and TGF- $\beta$ induce differentiation of Th17 cells (Mangan et al., 2006), whereas IL-23 is required for expansion and pathogenicity in vivo (Aggarwal et al., 2003). Recent studies suggest that IL-17 plays a role in the pathogenesis of coronary disease (Jafarzadeh et al., 2009; Liang et al., 2009; Hashmi and Zeng, 2006). Indeed, patients developing acute coronary disease showed increased IL-17 serum levels and those who evolved into a MI attained still higher levels than patients with only unstable angina. Authors suggested that IL-17 levels could be used as a predictor of the inflammatory activity within coronary vessels and therefore as a risk factor for coronary incidents (Jafarzadeh et al., 2009). This idea was highlighted by a recent study that evidenced an atherogenic role of IL-17A in a disease model in IL-17A (-/ ) mice (Chen et al., 2010). Although IL-17A activity may reflect the inflammatory activity within coronary vessels, our interest was to evaluate the activity of Th17 axis in response to acute MI and the subsequent process of myocardial remodelling. In fact, previous results in a MI model in mice indicated that IL-17A levels were only increased locally in the infarcted region (Timmers et al., 2008). Baldeviano has evaluated the role of IL-17A in myocardial remodelling in an animal model of experimental autoimmune myocarditis in IL-17A (-/-) mice (Baldeviano et al., 2010). Although IL-17A was not required for disease pathogenesis, it was related to the decrease of ventricular function and also to the development of dilated cardiomyopathy and subsequent heart failure. Further support to this idea comes from a study that showed an increase in Th17 cells in peripheral blood of patients with dilated heart disease, also implying a role for IL-17A in ventricular remodelling (Yi et al., 2009). Since we detected IL-17A expression in the MI-IR of LV associated with increased IL-6 and IL-23 expression at 1 week post-MI, our results suggest that activation of the IL-23/IL-17 axis may play a role in the pathophysiological process of the infarct scar remodelling. Positive staining for IL-17A in endothelial cells in the infarcted region after 1 week might be related to the expected effects triggered by post-MI inflammation on cell types and processes involved in cardiac repair, such as
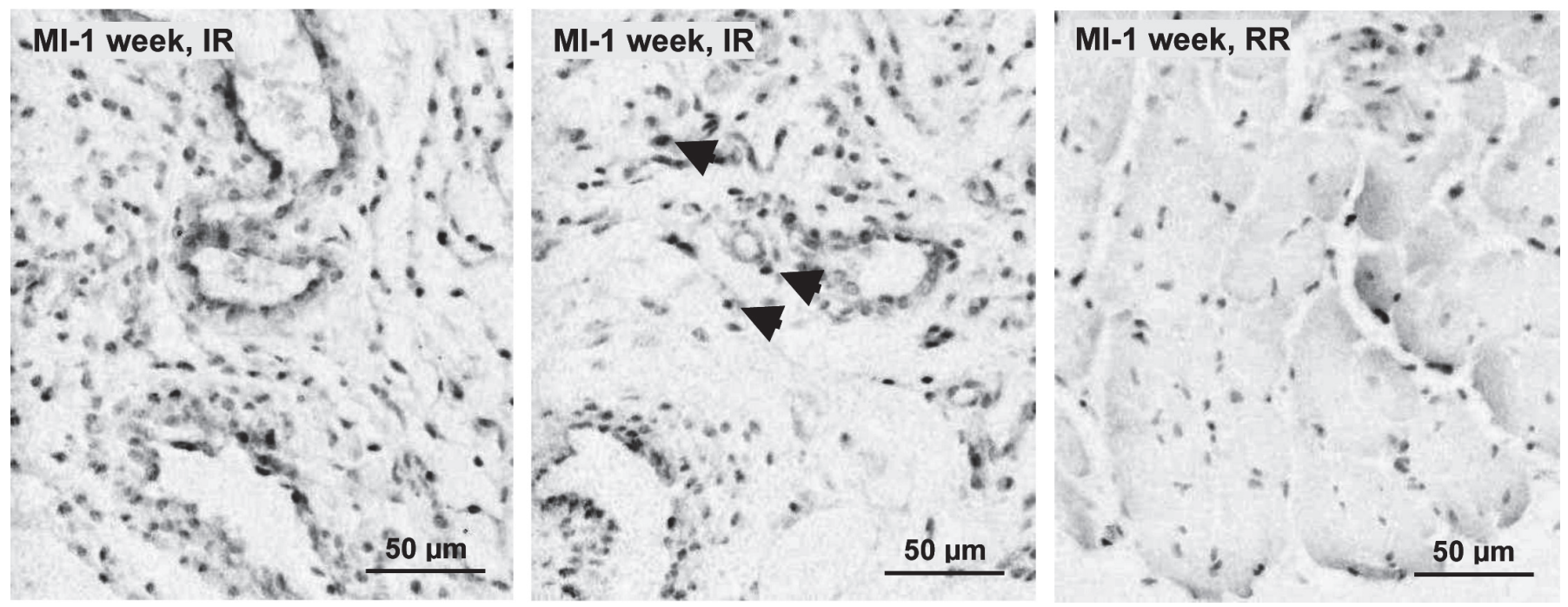

Figure 4: IL-17A localization on the infarcted region of the left ventricle (LV) by immunohistochemistry. Representative microphotographs of LV myocardium from infarcted (MI) rats at week 1 post MI. Left and middle: images of the infarcted region (IR) of the LV. As it is shown we found positive staining following an endothelial pattern in most areas of the infarction scar (left), with some small positive cells that were in the vicinity of blood vessels (arrows). Right: image of the remote non-infarcted region of the same group of animals (RR), cardiomyocytes can be seen without presence of positive staining on the remaining myocardium. 
enhanced leukocyte activation and adhesiveness, increased permeability of endothelial cells, acquisition of a matrixdegrading phenotype by fibroblasts, and also cardiomyocyte apoptosis (Frangogiannis, 2012). IL-17A has been recently described to contribute to myocardial ischemia/reperfusion injury by regulating cardiomyocyte apoptosis and neutrophil infiltration, with $\gamma \delta$ T lymphocytes as the main source of IL-17A (Liao et al, 2012). Since IL-17 expressed during inflammatory conditions is known to modulate the expression of matrix metalloproteinases (MMPs) that degrade collagen and mediate tissue remodeling (Cortez et al., 2007) it may also play a critical role in post-infarction myocardial remodelling, as shown in the case of postmyocarditis progression to dilated cardiomyopathy (Baldeviano et al., 2010).

\section{FUNDING}

This work was supported by Fondo Nacional de Desarrollo Científico y Tecnológico [postdoctoral Fondecyt 3080045 to A.M.A, Fondecyt-Fondap 15010006 to L.M., Fondecyt 1090223 to L.M.].

\section{ACKNOWLEDGEMENTS}

We would like to express our sincere gratitude and appreciation to Dr. Juan E. Carreño and to Dr. Elisa Marusic for their advice and assistance with the experimental model.

\section{CONFLICT OF INTEREST}

The authors declare no financial or commercial conflict of interest.

\section{REFERENCES}

AGGARWAL S, GHILARDI N, XIE MH, DE SAUVAGE FJ, GURNEY AL (2003) Interleukin-23 promotes a distinct CD4 $\mathrm{T}$ cell activation state characterized by the production of interleukin-17. J Biol Chem 278:19101914.

AWASTHI A, KUCHROO VK (2009) Th17 cells: from precursors to players in inflammation and infection. Int Immunol 21:489-498.

BAIDYA SG, ZENG QT (2005) Helper T cells and atherosclerosis: the cytokine web. Postgrad Med J 8:1746-1752.

BALDEVIANO GC, BARIN JG, TALOR MV, SRINIVASAN S, BEDJA D, ZHENG D, GABRIELSON K, IWAKURA Y, ROSE NR, CIHAKOVA D (2010) Interleukin-17A Is Dispensable for Myocarditis but Essential for the Progression to Dilated Cardiomyopathy. Circ Res 106:1646-1655.

BARRY SP, OUNZAIN S, MCCORMICK J, SCARABELLI TM, CHENSCARABELLI C, SARAVOLATZ LII, FAGGIAN G, MAZZUCCO A, SUZUKI H, THIEMERMANN C, KNIGHT RA, LATCHMAN DS, STEPHANOU A (2011) Enhanced IL-17 signalling following myocardial ischaemia/reperfusion injury. Int J Cardiol Oct 24. http://dx.doi. org / 10.1016/j.ijcard.2011.08.849

BHINDI R, WITTING PK, MCMAHON AC, KHACHIGIAN LM, LOWE HC (2006) Rat models of myocardial infarction. Pathogenetic insights and clinical relevance. Thromb Haemost 96:602-610.

CHEN S, SHIMADA K, ZHANG W, HUANG G, CROTHER TR, ARDITI M (2010) IL-17A is proatherogenic in high-fat diet-induced and Chlamydia pneumoniae infection-accelerated atherosclerosis in mice. J Immunol 185:5619-5627.

CHEN Y, LANGRISH CL, MCKENZIE B, JOYCE-SHAIKH B, STUMHOFER JS, MCCLANAHAN T, BLUMENSCHEIN W, CHURAKOVSA T, LOW J, PRESTA L, HUNTER CA, KASTELEIN RA, CUA DJ (2006) Anti-IL-23 therapy inhibits multiple inflammatory pathways and ameliorates autoimmune encephalomyelitis. J Clin Invest 116:1317-1326.

CHEN Z, LIN F, GAO Y, LI Z, ZHANG J, XING Y, DENG Z, YAO Z, TSUN A, LI B (2011) FOXP3 and ROR $\gamma$ t: Transcriptional regulation of Treg and Th17. In Immunopharmacol 11:536-542.
CHENG X, LIAO YH, GE H, LI B, ZHANG J, YUAN J, WANG M, LIU Y, GUO Z, CHEN J, ZHANG J, ZHANG L (2005) Th1/Th2 functional imbalance after acute myocardial infarction: coronary arterial inflammation or myocardial inflammation. J Clin Immunol 25:246-253.

CHENG X, YU X, DING YJ, FU QQ, XIE JJ, TANG TT, YAO R, CHEN Y, LIAO YH (2008) The Th17/Treg imbalance in patients with acute coronary syndrome. Clin Immunol 127:89-97.

CORTEZ DM, FELDMAN MD, MUMMIDI S, VALENTE AJ, STEFFENSEN B, VINCENTI M, BARNES JL, CHANDRASEKAR B (2007) IL-17 stimulates MMP-1 expression in primary human cardiac fibroblasts via p38 MAPKand ERK1/2-dependent C/EBP-beta, NF-kappaB, and AP-1 activation. Am J Physiol Heart Circ Physiol 293: H3356-3365.

DETEN A, VOLZ HC, BRIEST W, ZIMMER HG (2002) Cardiac cytokine expression is upregulated in the acute phase after myocardial infarction. Experimental studies in rats. Card Res 55:329-340.

FISHBEIN MC, MACLEAN D, MAROKO PR (1978) Experimental myocardial infarction in the rat. Am J Pathol 90:57-70.

FRANGOGIANNIS N (2012) Regulation of the Inflammatory Response in Cardiac Repair. Circ Res 110:159-173.

HARRINGTON LE, HATTON RD, MANGAN PR, TURNER H, MURPHY TL, MURPHY KM, WEAVER CT (2005) Interleukin 17-producing CD4+ effector $\mathrm{T}$ cells develop via a lineage distinct from the T helper type 1 and 2 lineages. Nature Immunol 6:1123-1132.

HASHMI S, ZENG QT (2006) Role of interleukin-17 and interleukin-17induced cytokines interleukin-6 and interleukin-8 in unstable coronary artery disease. Coron Artery Dis 17:699-706.

JAFARZADEH A, ESMAEELI-NADIMI A, NOUGH H, NEMATI M, REZAYATI MT (2009) Serum levels of interleukin (IL)-13, IL-17 and IL-18 in patients with isquemic heart disease. Anadolu Kardiyol Derg 9:75-83.

LANGRISH CL, CHEN Y, BLUMENSCHEIN WM, MATTSON J, BASHAM B, SEDGWICK JD, MCCLANAHAN T, KASTELEIN RA, CUA DJ (2005) IL-23 drives a pathogenic T cell population that induces autoimmune inflammation. J Exp Med 201:233-240.

LEVINE B, KALMAN J, MAYER L, FILLIT HM, PACKER M (1990) Elevated circulating levels of tumor necrosis factor in severe chronic heart failure. New Eng J Med 323:236-241.

LI B, LIAO YH, CHENG X, GE H, GUO H, WANG M (2006) Effects of carvedilol on cardiac cytokines expression and remodelling in rat with acute myocardial infarction. Int J Cardiol 111:247-255.

LIANG J, ZHENG Z, WANG M, HAN L, ZHENG Z, PENG J, LIU Z, WEI Y (2009) Myeloperoxidase (MPO) and interleukin-17 (IL-17) plasma levels are increased in patients with acute coronary syndromes. J Int Med Res 37:862-866.

LIAO YH, XIA N, ZHOU SF, TANG TT, YAN XX, LV BJ, NIE SF, WANG J, IWAKURA Y, XIAO H, YUAN J, JEVALLEE H, WEI F, SHI GP, CHENG $\mathrm{X}$ (2012) Interleukin-17A contributes to myocardial ischemia/reperfusion injury by regulating cardiomyocyte apoptosis and neutrophil infiltration J Am Coll Cardiol 24:420-429.

MANGAN PR, HARRINGTON LE, O'QUINN DB, HELMS WS, BULLARD DC, ELSON CO, HATTON RD, WAHL SM, SCHOEB TR, WEAVER CT (2006) Transforming growth factor-beta induces development of the $\mathrm{T}(\mathrm{H}) 17$ lineage. Nature 441:231-234.

MANN DL (2009) Inflammatory mediators and the failing heart, Past, present and the foreseeable future Circ Res 91:988-998.

METHE H, BRUNNER S, WIEGAND D, NABAUER M, KOGLIN J, EDELMAN ER (2005) Enhanced T-helper-1 lymphocyte activation patterns in acute coronary syndromes. J Am College Cardiol 45:19391945.

NIAN M, LEE P, KHAPER N, LIU P (2004) Inflammatory cytokines and postmyocardial infarction remodeling. Circ Res 94:1543-1553.

ONO K, MATSUMORI A, SHIOI T, FURUKAWA Y, SASAYAMA S (1998) Cytokine gene expression after myocardial infarction in rat hearts. Circ 98:149-156.

PARK H, LI Z, YANG XO, CHANG SH, NURIEVA R, WANG YH, WANG Y, HOOD L, ZHU Z, TIAN Q, DONG C (2005) A distinct lineage of CD4 T cells regulates tissue inflammation by producing interleukin 17 . Nature Immunol 6:1133-1141.

PASQUI AL, RENZO MD, PUCCETTI AL (2005) Cytokines in acute coronary syndromes. Int J Cardiol 105:355-356.

PFEFFER MA, PFEFFER JM, FISHBEIN MC, FLETCHER PJ, SPADARO J, KLONER RA, BRAUNWALD E (1979) Myocardial infarct size and ventricular function in rats. Circ Res 44:503-512.

SCHOEMAKER RG, URQUHART J, DEBETS JJ, STRUYKER BOUDIER HA, SMITS JF (1990) Acute hemodynamic effects of coronary artery ligation in conscious rats. Basic Res Cardiol 85:9-20. 
STEPPICH BA, MOOG P, MATISSEK C, WISNIOWSKI N, KÜHLE J, JOGHETAEI N, NEUMANN FJ, SCHOMIG A, OTT I (2007) Cytokine profiles and $\mathrm{T}$ cell function in acute coronary syndromes. Atheros 190:443-451

THYGESEN K, ALPERT JS (2007) White HD on behalf of the Joint ESC/ ACCF/AHA/WHF Task Force for the Redifinition of Myocardial Infarction. Universal definition of myocardial infarction. Eur Heart J 28:2525-2538

TIMMERS L, SLUIJTER JP, VAN KEULEN JK, HOEFER IE, NEDERHOFF MG, GOUMANS MJ, DOEVENDANS PA, VAN ECHTELD CJ, JOLES JA, QUAX PH, PIEK JJ, PASTERKAMP G, DE KLEIJN DP (2008) Toll-like receptor 4 mediates maladaptive left ventricular remodeling and impairs cardiac function after myocardial infarction. Circ Res 102:257-264.

YI A, JIAN L, XIAOJING H, HUI X (2009) The prevalence of Th17 cells in patients with dilated cardiomyopathy. Clin Invest Med. 32:E144-E150.

YIN FC, SPURGEON HA, RAKUSAN K, WEISFELDT ML, LAKATTA EG (1982) Use of tibial length to cuantify cardiac hypertrophy: application in the aging rat. AJP-Heart 243: H941-H947. 